Memorias de la consolidación del Estado a partir de la distribución de la tierra pública en Neuquén, Argentina

\title{
MEMORIAS DE LA CONSOLIDACIÓN DEL ESTADO A PARTIR DE LA DISTRIBUCIÓN DE LA TIERRA PÚBLICA EN NEUQUÉN, ARGENTINA
}

\author{
Memories of the consolidation of the state and the distribution \\ of public land in Neuquén, Argentina
}

\author{
Lara Bersten*
}

\section{RESUMEN}

Este trabajo busca poner de relieve el proceso de ocupación y distribución de la tierra en Villa Traful, Neuquén, Argentina. Para ello se tienen en cuenta tres elementos. El primero es el análisis del proceso de avance y ocupación de las tierras en Norpatagonia por parte del Estado. El segundo la experiencia de los sujetos que habitaban Traful previa y posterior ocupación del territorio por parte del Estado. El tercero, la relación de estos sujetos con los primeros propietarios de la zona. Este análisis se encuentra atravesado por categorías que se fueron creando a medida que se desplegó el andamiaje burocrático estatal, las cuales a su vez delinearon la subjetividad de los habitantes norpatagónicos: las nociones de pionero, ocupantes precarios, intrusos y primeros pobladores. La metodología abordada en este trabajo parte del análisis de fuentes históricos documentales, cruzado con el trabajo de campo realizado en la localidad. Este recorrido permite observar el modo de construcción del territorio por parte del Estado y de qué manera subvirtió otros tipos de ocupación territorial.

Palabras clave: Estado-Nación, territorio, propiedad.

\footnotetext{
* Instituto de Ciencias Antropológicas, Universidad de Buenos Aires. Buenos Aires, Argentina. Correo electrónico: larabersten@gmail.com
}

Artículo recibido el 15 de julio de 2016. Aprobado el 15 de diciembre de 2017. 


\begin{abstract}
The purpose of this work is to display the process of occupation and distribution of land in Villa Traful, Neuquén, Argentina. In order to do so, we will consider three elements. First, we will analyze the process of occupation in north Patagonia. Second, we will consider the experience of the inhabitants of Traful previously and after State occupation. Third, the relationship of these inhabitants with the first owners of the area. Throughout the analysis we will manage the categories of people created by the state bureaucratic scaffolding that shapes the subjectivity of the north Patagonia inhabitants: the notions of pioneer, precarious occupants, intruders and first settlers. The following study starts from historical documents as sources of analysis together with the fieldwork carried out on location. This allows us to observe the way the land was developed and the manner it changed other types of territorial occupation.
\end{abstract}

Keywords: Nation State, territory, property.

\title{
Introducción
}

La investigación que enmarca este trabajo se centra en Villa Traful, ubicada en el Departamento Los Lagos, extremo sur de la provincia de Neuquén, Argentina. Al igual que otras zonas de la región, previa centralización y consolidación del Estado-Nación, Traful se encontraba poblada por familias indígenas que mantenían un circuito regional transcordillerano, lo anterior hasta avanzado el siglo XX.

Este proceso local de ocupación y distribución de la tierra debe ser analizado en el contexto regional y vinculado con la consolidación del Estado, las políticas nacionales y a partir de mediados del siglo XX con las políticas provinciales. Al reflexionar sobre el proceso de ocupación y distribución de la tierra adquiere centralidad la noción de territorio, la cual fue abordada en profundidad por Lefevbre (1974). Este sociólogo brindó importantes aportes para comprender la noción de lugar, espacio y territorio e introdujo la diferenciación entre espacio fijo y delimitado, y el espacio como totalidad que 
se fragmenta a partir de la construcción territorial. Esta concepción del espacio como totalidad remarca la noción de experiencia -como espacio vivido y enraizado- e intenta superar las nociones que entendían al territorio como superficie o escenario de las relaciones sociales ${ }^{1}$.

Desde esta perspectiva, la consideración del territorio como construcción social implica que este no es algo dado, sino que abarca una multiplicidad de fenómenos de índole económica, política e ideológica que pueden entrar en contradicción. Por lo tanto, para analizar el proceso de incorporación y segmentación de este espacio patagónico, recupero la tipología de territorios esbozada por Fernandes (2010), deudora de los análisis de Lefebvre, la cual me es útil para analizar de qué manera durante el período de consolidación del Estado argentino este se fue expandiendo sobre diferentes espacios, clasificándolos y segmentándolos, así como imponiendo una visión hegemónica en relación a la delimitación y uso del terreno.

La tipología propuesta por Fernandes (2010) pretende integrar en la concepción de territorio los intereses puestos en juego, las acciones, relaciones y conflictos, superando así la visión simplista que homologa al territorio con el

\footnotetext{
${ }^{1}$ Existen múltiples debates en el campo de la geografía con respecto de la categoría de territorio. Uno de los pioneros fue Ratzel a fines del siglo XIX quien lo asimiló con el Estado-Nación (Bustos Ávila, 2009). Obras más actuales como la de Moraes (2002) se plantean en una línea de continuidad afirmando que: "[...] el territorio es el ámbito espacial de ejercicio del poder del Estado" (2000: 42). Por su parte, la crítica marxista de Lefebvre en "La producción social del espacio" apunta a que el Estado capitalista representa el rol hegemónico de la burguesía, y que esto se lleva adelante no sólo por medio del uso de la violencia en la apropiación territorial, sino también por medio del saber (Lefebvre, 1974: 17). El sociólogo francés plantea una teoría del Estado a partir de la cual argumenta que la expansión territorial fue una de las principales transformaciones ocurridas en el siglo XX. De este modo, su definición del territorio introdujo dimensiones simbólicas y afectivas señalando la complejidad del mismo y enfatizando la inexactitud que reside en el hecho de pensar al territorio de manera factual o a partir de la homologación con el espacio fijo o delimitado. Harvey (2006), en esta misma línea, introdujo que el territorio y la apropiación de este se da en el contexto del Estado moderno, el cual surge como representante de la burguesía, pero que debe asumir una existencia independiente u objetiva, y que se presenta como garante del interés común. En este sentido, retoma a Marx y Engels para plantear que la clase dirigente del Estado utiliza instrumentos de dominación con el fin de: "[...] ejercer el poder para su propio interés de clase, mientras afirma que sus acciones son para el bien de todos" (Marx y Engels, 1970, citado en Harvey, 2006: 80), transformando así los intereses de clase en un interés general ilusorio (Harvey, 2006: 81).
} 
espacio de gobierno. Para esto, propone en primer lugar, la separación analítica entre territorios materiales e inmateriales y al primero lo subdivide en tres: a) Espacios de gobernanza (Estados, provincias, municipio, etc.); b) La propiedad (contemplando diferentes tipos de propiedad) y c) Las territorialidades que comprende las formas tradicionales de habitar el espacio, las formas de uso de los actores locales. Si bien esta diferenciación permite observar las especificidades de cada uno, se señala que estos solo existen en su interrelación (Fernandes, 2010: p. 16). Esta consideración es de utilidad para observar la superposición y complejidad presente en la localidad de estudio e ir identificando de qué forma, en la construcción del espacio, se fueron superponiendo diferentes tipos de territorialidades. Estimo que esta herramienta posibilitará observar el modo en que la segmentación y construcción de dicho espacio también ha sido una segmentación particular de la naturaleza y de los recursos².

El proceso de investigación fue realizado a través de la implementación de las estrategias metodológicas propuestas desde la Antropología Social, por medio de las cuales se enfatiza en la perspectiva cualitativa. Se entiende, por lo tanto, que el mundo social se constituye a partir de relaciones complejas y contradictorias en permanente movimiento; es por esto que para captar dicha complejidad se incorporan diferentes niveles de análisis de manera dialéctica (Achilli, 2004). Se posa la mirada en la escena microsocial en articulación con las dinámicas estructurales y procesuales. Esta perspectiva parte de la suposición de que todo proceso social humano se desarrolla inscrito en relaciones a partir de las que se constituyen experiencias, las cuales se expresan en una subjetividad particular de carácter relacional (Bourdieu, 2002).

Por tanto, retomo el trabajo de campo como instancia fundamental de

\footnotetext{
${ }^{2}$ En este artículo se recupera la propuesta de Fernándes, dado que nos resulta de utilidad para el trabajo analítico en nuestro caso de estudio, sin pretender reducir el volumen y relevancia de los debates respecto de la noción de territorio que surgieron en el campo de la geografía y se expandieron a otras disciplinas sociales.
} 
un proceso más amplio de construcción de conocimiento. Las técnicas que utilizadas en esta investigación son las habituales en Antropología Social: entrevistas abiertas, semi-estructuradas, en profundidad-elaborando asimismo guías de preguntas abiertas a partir de los objetivos de investigación-, técnicas de observación con y sin participación. El trabajo de campo se realizó entre los años 2006 y 2011. Por otra parte, también recupero para el análisis aportes de la Antropología Histórica, es decir, que el trabajo realizado con fuentes se hace además cargo de preguntas antropológicas. Las fuentes utilizadas son: documentación oficial de las administraciones públicas nacionales y provinciales tales como fichas censales de la APN, Censo Ganadero, Censos Nacionales, las que permitieron cuantificar y cruzar la información del trabajo de campo con aquella producida por diferentes instituciones.

\section{¿Por qué contar el proceso de creación de Villa Traful y la consolidación de la propiedad?}

Desde el año 2003 y a partir del impulso dado al Consejo Nacional de Investigaciones Científicas y Técnicas (CONICET) surgieron nuevas camadas de investigadores, multiplicando los estudios en Norpatagonia en el ámbito de la investigación, transferencia y extensión universitaria. En este contexto, en el año 2006, con un grupo de investigadores de la UBA, fuimos convocados por la Biblioteca Popular de Villa La Angostura (Neuquén, Argentina) para realizar un trabajo de relevamiento de la memoria histórica de los pobladores del Parque Nacional Nahuel Huapi ${ }^{3}$. Bajo la dirección de Juan Carlos Radovich y la coordinación de Sebastián Valverde, dimos inicio al trabajo en la región. Esto nos posibilitó ir tomando contacto y observar las particularidades de diferentes localidades vinculadas al PNNH, así como también de otras zonas de Norpatagonia. En este sentido, las miradas globales y particulares con

\footnotetext{
${ }^{3} \mathrm{PNNH}$ de ahora en adelante.
} 
relación al territorio - la propiedad, la construcción del Estado y las categorías identitarias- han sido delineadas por esas experiencias.

Al llegar a la localidad de Villa Traful nos encontramos con un territorio que en algunos aspectos podía ser homologable a otras situaciones de la región y en otros casos mostraba algunas diferencias. Villa Traful, rodeada por el PNNH, es una localidad que se encuentra relativamente aislada, ya que si bien se ubica a $100 \mathrm{~km}$ de San Martín de los Andes y de Bariloche, y a solo $60 \mathrm{~km}$ de Villa La Angostura, su altitud de 717 metros y el camino de ripio por el cual se accede al pueblo dificulta la comunicación. Por otra parte, su historia se encuentra vinculada directamente a la Administración de Parques Nacionales ${ }^{4}$ referente del Estado-Nación en la región. Esta localidad neuquina insertada en un territorio nacional conllevó diversas disputas respecto de la apropiación y administración del espacio que continúan hasta el presente. Esta particularidad explica que la compraventa de tierras en la zona haya permanecido prácticamente la misma que a principios del siglo XX, sin grandes cambios en las familias del pueblo.

Al iniciar el trabajo de investigación, las preguntas, dudas, inquietudes se orientaron en un principio hacia la vinculación/conexión con la identidad indígena. Sin embargo, si bien la mayoría de los pobladores, en sus relatos, rememoraba y reivindicaba un pasado indígena, estos recuerdos no se transformaron en una adscripción presente. Esto es una importante diferencia con otras zonas de la región en las que se han incrementado los procesos etnopolíticos y de etnogénesis. En el caso de Traful, sus pobladores se identifican con categorías que fueron implementadas por el Estado tales como "pioneros", "primeros pobladores", "primeros pobladores blancos", las cuales por supuesto tienen un sentido local. Es por esto que las categorías utilizadas en este trabajo son aquellas que adquieren sentido en la dinámica de la vida social

\footnotetext{
${ }^{4} \mathrm{APN}$ de ahora en adelante.
} 
de los trafulenses (Bersten, 2014a).

En el marco de los trabajos en conjunto con las organizaciones locales y el municipio publicamos dos libros: Relatos Patagónicos. Historias familiares en la construcción del espacio social en Villa Traful(Valverde, García y Bersten, 2008) y El territorio en perspectiva. Política pública y memoria social en Villa Traful (García y Bersten, 2009). Estas publicaciones buscan recuperar, a través de la indagación en las historias de vida de sus habitantes y la sistematización de fuentes documentales, la memoria social de Villa Traful en articulación con las políticas públicas desarrolladas en esa localidad que han ido delineando el espacio social en el contexto de conformación y expansión del Estado-Nación argentino. Estos trabajos fueron las primeras publicaciones sobre la zona y casi la totalidad de los ejemplares fueron entregados a sus habitantes e instituciones locales. También se realizó un video: "Villa Traful. Recuerdos y relatos de sus pobladores", así nombrado por los habitantes del pueblo.

Dada la inexistencia de publicaciones los primeros trabajos se nutrieron fuertemente de los aportes regionales. Sin embargo, al continuar mi investigación doctoral en la localidad fui profundizando el trabajo de campo y de archivo lo que me permitió describir y analizar diferentes problemáticas de la Villa a partir de su propia especificidad. Es por esto que el presente artículo realiza una descripción empírica del proceso de consolidación de la propiedad en la localidad de Traful orientada por las categorías de territorio (citadas previamente), otorgándole centralidad a la especificidad del caso ${ }^{5}$.

\footnotetext{
${ }^{5}$ Esto no pretende desconocer el volumen y relevancia de las investigaciones en la zona, las cuales han sido abordadas en otros trabajos. Para un estudio sobre la localidad desde un enfoque regional, véase: Bersten (2009, 2014a, 2014b), García y Bersten (2009), Valderde, García y Bersten (2008).
} 
Incorporación de la Patagonia al Estado argentino y la consolidación de la propiedad privada

Hasta fines del siglo XIX, lo que hoy es la "Patagonia argentina" conformaba un extenso territorio natural y social, habitado por pueblos originarios, el cual se integraba en dinámicos circuitos regionales tras la cordillera. Una vez consolidado el Estado argentino, los grupos gobernantes se abocaron a la organización del Estado generando las condiciones materiales para su expansión: el avance sobre las "fronteras internas" en territorios ocupados por población originaria y la consolidación de la soberanía sobre los límites del Estado -heredados de la Colonia-. Esta expansión territorial permitiría aumentar la producción intensiva en el contexto de la inserción de la Argentina al mercado internacional.

En 1878, se iniciaron sucesivas acciones militares, conocidas popularmente como "Campaña al Desierto", financiadas por medio de la "Ley de Empréstito" No 947 (1878). Por medio de esta ley se lanzó una suscripción pública que otorgaba como contrapartida bonos que posteriormente podían ser intercambiados por las tierras conquistadas (Golab y Lamperti, 2005). Se establecía así que gran parte de las tierras serían transferidas a privados. Una vez incorporada la Patagonia bajo dominio estatal y consolidada la propiedad privada, el poder central (desde Buenos Aires) propuso la creación de los "Territorios Nacionales" consolidando así el territorio como espacio de gobernanza, quedando subsumidas otras territorialidades.

Luego de la "Campaña al Desierto", se llevó a cabo el proceso de distribución de la tierra. Para esto, se implementó un conjunto de leyes, decretos y resoluciones relativos a la tierra pública que, sumados a la "Ley de Empréstito", tuvieron una clara incidencia en la distribución de la propiedad en las últimas dos décadas del siglo XIX y terminaron por consolidar los latifundios en Patagonia. 
La política de distribución de la tierra benefició indiscriminadamente a grupos vinculados a las elites porteñas -en su mayoría ganaderos bonaerenses e ingleses- generando un mecanismo idóneo para el acaparamiento y la especulación. Como contracara, el acceso a la tierra para los pobladores criollos e indígenas y para los inmigrantes sin capital fue en cambio muy difícil por la especulación característica de las empresas y la falta de apoyo del Estado (Blanco, 2007).

Pese a la entrega de gran cantidad de tierras neuquinas, no toda se privatizó. Una gran parte se mantuvo en manos de ocupantes sin título (fiscaleros), transformados en crianceros trashumantes en condiciones de marginalidad social. Estos últimos ocupaban territorios "de hecho" y pasaron a ser considerados como "intrusos" por la legislación vigente, siendo a su vez el tipo de ocupación mayoritaria. Asimismo, muchos de estos "intrusos" fueron desplazados por los nuevos propietarios y arrendatarios, con el fin de justificar las exigencias de poblar e introducir capital para el desarrollo de la Patagonia -los obligaban las leyes de distribución de tierras públicas en vigencia-. No obstante, dada la marginalidad, precariedad y negación hacia este tipo de ocupaciones, no existen registros documentales precisos.

Esta situación se modificó en 1925 durante el gobierno del entonces presidente Yrigoyen, dado que decidió suspender la adjudicación de tierras en propiedad y autorizar a la Dirección General de Tierras y Colonias ${ }^{6}$ a otorgar "Permisos Precarios de Ocupación y Pastaje", reconociendo la ocupación y generando una legislación que reconoce a algunos ocupantes y a otros no -los que permanecen "intrusos"-. Los PPOP estaban sujetos a la decisión gubernamental, lo que posibilitaba que quien tenía este permiso podía pasar a ser intruso si el gobierno lo determinaba. No obstante, esta medida les otorgó un marco de legalidad a las ocupaciones existentes.

${ }^{6}$ DGTC de ahora en adelante.

${ }^{7}$ PPOP de ahora en adelante. 
En este período fundacional, las elites políticas y económicas representadas en el gobierno fueron creando un conjunto de herramientas institucionales dentro del marco del Estado por medio de las cuales "legalizaron" la desigualdad. Esta desigualdad dividió a la sociedad entre unos pocos grupos propietarios y el resto de la población, lo que limitó la aparición de sectores de medianos y pequeños propietarios rurales (Blanco, 2007). Esta diferenciación resultó central en el modo en que se configuraron las relaciones en Traful desde épocas tempranas, diferencias que aún permanecen articulando parte de la dinámica local.

Hacia fines del siglo XIX y contradiciendo las crónicas militares que sostenían que esta tierra había sido "librada de indios", en la primera mensura realizada en el año 1884 -que aparece denominada como "sección XXXIX"se detallan al menos tres tolderías u ocupaciones. En el censo del año 1914, en el departamento Los Lagos -el cual incluye a la zona de Traful- se registró la existencia de una población total de 3.254 habitantes - de los cuales más de la mitad eran extranjeros-. En el censo de 1919, los datos de Traful aparecen desagregados, registrándose una población rural de 138 habitantes.

Respecto de la distribución de la tierra, cabe señalar que la región que se considera en este trabajo también se vio afectada por la Ley de "Premios Militares" $\mathrm{N}^{\mathrm{o}} 1628$ (1885). A través de esta se entregaron bonos intercambiables por tierras, a quienes llevaron a cabo la campaña militar, los cuales en su mayoría fueron cedidos a terceros a un precio extremadamente bajo. Muchos concesionarios reunieron así una gran extensión en bonos, cuya ubicación era elegida y solicitada al Estado. Este es el caso de George Newbery, primer propietario de Traful, quien creó la estancia "La Primavera". También, en las cercanías se estableció Jarred Augusto Jones -los dos de nacionalidad estadounidense-. Ambos se instalaron y desarrollaron importantes explotaciones ganaderas en el departamento Los Lagos (Bersten, 2014a; Silveira y Guindon, 2008).

La adjudicación de títulos de propiedad en Traful desconocía que estos 
territorios ya se encontraban habitados y fueron justamente los pobladores sobrevivientes a la "Campaña al Desierto" que pasaron a ser denominados intrusos y en algunos casos adjudicatarios de PPOP. Como se mencionó previamente, la obtención de los PPOP implicó cierto reconocimiento legal, pero esto no los protegía de eventuales expulsiones y además suponían una infinidad de trabas para sus ocupantes (Bersten, 2014a y b). Asimismo, esta autorización para permanecer en los territorios fiscales fue obtenida a partir del reconocimiento de la ciudadanía argentina, condición sine qua non para usufructuar estas tierras.

Se señala por tanto que en la medida que se fueron creando las herramientas institucionales para la consolidación de este espacio como territorio de gobernanza, también se inició el proceso de privatización de la tierra. Resulta entonces interesante observar con respecto a este período de consolidación de estatalidad local que, en las memorias de los pobladores, sus recuerdos, se entremezclan los cambios en su vida cotidiana con el proceso de la consolidación de la propiedad.

\section{La territorialidad de los pobladores de Traful}

Los primeros relatos de la zona se sitúan con posterioridad a la avanzada militar de fines del siglo XIX. En contraposición a los pioneros, ninguno de los pobladores obtuvo título de propiedad quedando así como “ocupantes". El poblamiento de la zona que rodea al lago Traful fue un proceso lento, durante el cual distintas familias campesinas -mayoritariamente indígenas-registradas en los escasos documentos de la zona y recordadas por sus descendientes se fueron asentando. Para el organismo encargado de administrar la tierra en aquel entonces, "Dirección de Tierras y Colonias", estos pobladores fueron los ocupantes que recibieron los "permisos precarios de ocupación”.

Al recuperar los relatos de vida, se evidencia la dificultad de 
circunscribirlos estrictamente a la localidad de Villa Traful. Esto responde, en primer lugar, a que las historias familiares son previas a la creación oficial de Villa Traful. En segundo lugar, muchas de las actuales familias trafulenses se desplazaban por el territorio, con el objetivo de intercambiar mercancías, realizar trabajos temporarios, entre otros. Es decir que la territorialidad $-\mathrm{O}$ el espacio apropiado por los sujetos-se definía en base a la movilidad involucrando fundamentalmente dos destinos: Chile y en menor medida la zona de San Martín de los Andes. A medida que avanzó el siglo XX esta movilidad se fue modificando y generalmente los circuitos a los que refieren los pobladores son más pequeños. No obstante, exceden la localidad de Traful involucrando a Cuyín Manzano y Pichi Traful (Ver mapa Nº1).

Según los pobladores de la zona, los primeros en instalarse en la zona a fines del siglo XIX fueron los Paichil y los Inalef. Posteriormente, en los primeros años del siglo XX llegaron otras familias también reconocidas como primeros pobladores, categoría que refiere a las personas que habitaron y construyeron el pueblo -tema que se abordará en profundidad más adelanteHasta la década de 1940, el poblamiento del espacio continuó de manera lenta y gradual, arribando en su mayoría chilenos e indígenas, dedicados a la vida campesina. En este sentido los primeros pobladores, hacen referencia a un pasado mapuche imbricado con un contexto regional transcordillerano.

El espacio habitado por cada familia es denominado como población. En aquel entonces, cuando aún no existían alambrados, los límites entre unas y otras se establecían a partir de accidentes geográficos. De hecho, a medida que se confeccionaron estudios cartográficos, los cerros, arroyos, cascadas, etc., fueron recibiendo denominaciones que los identificaban con las poblaciones de referencia. Así, el "cerro Painepe" forma parte de la población correspondiente a la familia mencionada. También estaban marcados todos los puertos con el nombre de las familias residentes. De esta forma, los mapas registran la antigüedad de estas ocupaciones y legitiman su preexistencia como colonos - 
aun cuando estos fueran posteriores a la creación del PNNH- (Ver mapa $\left.\mathrm{N}^{\mathrm{o}} 2\right)$. Finalmente, en 1914 la Dirección Nacional de Tierras y Colonias encargó un relevamiento al ingeniero geógrafo Emilio Frey a partir del cual se modificaron dichas nomenclaturas por otras (Silveira y Guindon, 2008). Estos cambios en la denominación cobran relevancia en tanto que cartografiar, describir y relatar el espacio constituyen formas de configurar el territorio, establecer sus límites, constituir el Estado-Nación a partir del ejercicio efectivo de una soberanía política y cultural (Moyano, 2003).

Al instalarse en la zona, las familias debieron generar las condiciones para poder garantizar su subsistencia; así los pobladores recuerdan ese otro tiempo con orgullo y heroísmo, ya que para asentarse allí debieron abrir claros "a hacha" y con pequeños incendios controlados que permitieron hacer habitable dicho espacio: "Acá se hacía a fuerza de picota, había que arrancarle los michayales, todo esto que usted ve limpio lo hicieron los viejos nuestros acá mismo. Esto lo limpiaron y lo araron" (Edgardo, poblador de Villa Traful, Registro de Campo en Villa Traful, año 2009).

Las ocupaciones se realizaban en porciones del territorio longitudinales desde el cerro hasta el lago, vinculado a la crianza de animales bajo la modalidad trashumante. Las construcciones eran de madera -generalmente en canoga, palo de ciprés achatado-, con aberturas pequeñas y pisos de tierra apisonada. Los techos de las casas se realizaban en ángulos muy agudos para favorecer el escurrimiento de la nieve. Este tipo de edificaciones aún existen en la zona de Traful. Al interior solían encontrarse las "cocinas económicas" a leña que continúan utilizándose dado que cumplían la doble funcionalidad de cocinar y calefaccionar el hogar.

Los habitantes de Traful se caracterizaron tradicionalmente por llevar adelante una economía de subsistencia basada en la cría de animales y el mantenimiento de huertas estacionales para el autoconsumo - sembraban avena, maíz, papa, frutillas, etc.-. Las huertas y las casas generalmente se encontraban 
rodeadas de álamos, árboles de gran altura, plantados con el objetivo de protegerlas de los vientos patagónicos. La ganadería se vio fuertemente afectada por las condiciones climáticas, por lo tanto, para llevarla adelante las familias crianceras debieron encontrar estrategias adecuadas a la situación. Para esto dividieron el ciclo ganadero en invernada y veranada. Durante el invierno, las familias residían en los territorios bajos y en época estival los animales marchaban en busca de alimento hacia zonas altas donde se encuentran pastos más tiernos. Los pobladores construían dos casas, una arriba y otra abajo, que señalan espacios y tiempo de residencia diferenciales marcados por el ciclo productivo. Durante las veranadas, las mujeres realizaban queso, manteca; cocinaban su propio alimento y lo administraban por medio de la elaboración de conservas tales como: dulces, frutas secas o charqui en el caso de la carne. Otro de los modos usuales de preservación consistía en algo muy simple: se dejaban los alimentos perecederos en el exterior y el frío patagónico realizaba el resto. Para esto construían una especie de caja de madera cubierta por malla de alambre para evitar que se acercaran animales o insectos. Otra forma de almacenamiento se hacía por medio de la utilización del "chenque" que consistía en un pozo tapado con paja o madera funcionando como una especie de despensa debajo de la tierra. También confeccionaban jabones y velas con grasa, en aquel entonces único medio de iluminación en las viviendas.

A principio de siglo este desplazamiento invierno/verano lo realizaba la familia completa, aunque poco a poco, tras la configuración del espacio de gobernanza, se fue modificando. De las familias que continúan marginalmente con la actividad solo van uno o dos integrantes. Se estima que esto se debió a la presencia de instituciones que fueron regulando la vida cotidiana, como por ejemplo la escuela, limitando la movilidad y sedentarizando a las familias, como así también las formas de contratación laboral permanente -como el empleo público- que impidieron una licencia estival completa.

Las condiciones climáticas extremas de la zona traen a los recuerdos de 
los pobladores momentos difíciles tales como pérdida de las cosechas, muerte de los animales. Estas experiencias extremas que involucran temporales no solo son vívidas como recuerdos de la memoria, sino que también permanecen como marcas corporales, marcas físicas dejadas por el intenso frío en los primeros pobladores y crianceros de la Patagonia.

Además de la producción de alimentos y de procurarse los medios para garantizar su salud por medio de la utilización de hierbas medicinales, los pobladores también realizaban su propia vestimenta. La confección de sus ropas era producto de técnicas autóctonas. Para la obtención de productos que no podían manufacturar recurrían al intercambio entre vecinos e incluso se conformó un circuito que tenía a la estancia "La Primavera" como locus principal. Otra de las formas de intercambio y comercio que recuerdan los trafulenses son los mercachifles, quienes a medida que fueron mejorando los caminos accedieron a la localidad. Estos vendían e intercambiaban mercadería a domicilio, hasta que con el correr de los años se fueron instalando proveedurías.

Esta zona estaba caracterizada por el aislamiento, característica que, en menor medida, persiste en el presente. La comunicación con los pueblos próximos se realizaba con la ayuda de caballos y bueyes. Aun cuando en la década del 1930-1940 comenzaron a llegar vehículos a la Patagonia, durante las heladas no podían entrar a la zona de Traful por las condiciones en las que se encontraban los caminos. Los viajes en aquel entonces eran difíciles, tomando a veces varios días; la mercadería era transportada en pilcheros (a caballo) o catangos (con bueyes). Para quienes estaban allí asentados, una de las formas más sencillas de comunicación, aunque no menos esforzada, fue la utilización de embarcaciones por medio de los cuales accedían por vía marítima a otros poblados próximos.

Las ocupaciones de los pobladores fueron validadas desde fines del siglo XIX por la Dirección Nacional de Tierras y Colonias, reconociéndolas a través de los PPOP, categorizando a los no reconocidos como "intrusos". 
Los adjudicatarios de los PPOP debían pagar los impuestos fijados por esta institución.

Con la creación de la APN en 1934 y del Parque Nacional Nahuel Huapi, este territorio quedó bajo esta jurisdicción. A partir de esto se le dio un fuerte impulso a la región, lo que hizo que se instalaran en la zona nuevos habitantes, de la mano de las concesiones y licitaciones de la APN. A partir de esta situación se instalaron dos aserraderos que emplearon a gran cantidad de trabajadores en el área. La explotación de la madera estaba destinada a la construcción y a vialidad. Los emprendimientos se mantuvieron hasta el año 1948 en que fueron prohibidos por la APN.

La dinámica de vida comenzó a cambiar a partir de la constitución del parque. Muchos habitantes fueron relocalizados y sus modos de vida controlados y estigmatizados. Una de las primeras medidas fue el control y regulación de las actividades de los crianceros, lo que hizo disminuir abruptamente dicha actividad en los terrenos administrados por la APN. Las familias asentadas en la zona tenían vínculos sociales entre sí, y también casi todas relaciones de parentesco. Los pobladores cuentan que se juntaban para celebrar las fechas patrias, el día de los santos, cumpleaños, fin del ciclo lectivo, el carnaval, entre otros. La población se ha mantenido relativamente estable, rondando los 300-400 habitantes. A lo largo del trabajo de campo, hemos entrevistado a integrantes de todas las familias de primeros pobladores vinculadas casi en su totalidad por medio de relaciones de parentesco.

\section{Los pioneros y la estancia "La Primavera"}

Newbery nació en New York, en 1856, de profesión odontólogo. Una vez llegado a la Argentina ocupó el cargo de vicecónsul de los Estados Unidos en Buenos Aires, y posteriormente fue dentista personal de Julio A. Roca. La estrecha relación que construyó con este último le facilitó la obtención de los 
beneficios de las leyes de premios militares que lo convirtieron en el primer propietario de la zona de Traful donde conformó la estancia "La Primavera" (Ver mapa $N^{0}$ 1) que con la creación del Parque Nacional Nahuel Huapi en 1936 quedaría al interior de esta jurisdicción. Sin embargo, lo que se omitió es que en el predio otorgado a Newbery -de alrededor de 10.000 hectáreas- ya había personas viviendo, por lo tanto, los nuevos propietarios establecieron con ellos acuerdos de "medieros", es decir, los ocupantes sin título debieron comenzar a entregar parte de lo cosechado y animales como condición de permanencia en el lugar.

Newbery contrajo matrimonio con Fanny Taylor, también de origen estadounidense, quien tenía tres hermanos: Judson, Santiago y James, a los que les facilitó la instalación en Traful. Una vez allí, estos se dedicaron a la siembra y crianza de animales y luego de algunos años, Newbery les transfirió su propiedad. Con los Taylor a cargo, se desdibujaron los acuerdos preexistentes convirtiendo a los "medieros" en peones. Los pobladores se opusieron, lo que tensó la situación. En 1911 los propietarios decidieron desalojar a parte de estas familias, para lo cual la metodología implementada, según cuentan los pobladores de la zona, fue el incendio de las casas imponiendo así su autoridad en el territorio ${ }^{8}$.

Luego de este episodio y otras situaciones de violencia que involucran a esta familia, rememoradas por los pobladores, la estancia fue vendida en 1923 a un inglés llamado Henry Bell quien delegó la administración a Guy Dawson. Este la acondicionó para recibir huéspedes comenzando así a surgir una corriente ininterrumpida de visitantes aficionados a la pesca (Silveira y Guindon, 2008: 121). En el año 1935 la estancia fue comprada a Bell por Felipe Larrivier -durante un viaje a Inglaterra-. Este último era de origen francés,

\footnotetext{
${ }^{8}$ En el libro Historias de la Patagonia (2005) del periodista rionegrino Francisco Juárez, se menciona de hecho a los hermanos Taylor, los cuales habían ganado "fama" en la zona por su accionar violento con los pobladores.
} 
de profesión militar y se había radicado en Argentina como agregado militar de la embajada francesa en Buenos Aires, luego de contraer matrimonio con una criolla perteneciente a la aristocracia argentina. "La Primavera" recibió visitantes y tuvo una importante conexión con sectores militares, así como también con el ámbito del arte y la literatura.

La estancia continuó en manos de Felipe Larrivier hasta su muerte en el año 1994 y la heredaron sus dos hijos quienes la subdividieron. La parte este del lago quedó en poder de Felipe (hijo) y mantuvo el nombre "La Primavera", con un total de 4.487 hectáreas, aunque poco tiempo después fue vendida al millonario norteamericano, dueño del canal de noticias CNN, Ted Turner. La margen izquierda del río Traful quedó en poder de Mauricio, quien llamó a su estancia "Arroyo verde", con un total de 5.000 hectáreas permaneciendo hasta la actualidad en manos de esta rama de la familia Larrivier.

"La Primavera", primera propiedad privada de la zona, se materializó a partir de "los alambrados" que delimitaron un adentro y un afuera, un señalamiento acerca de las zonas en donde "no" podían instalarse los pobladores. Es común escuchar: "Nos empezaron a correr los alambrados". En aquel entonces, este hecho concretó el concepto de frontera, de lo público y de lo privado, de propiedad y de derecho. El Estado como garante de la propiedad privada restringió la posibilidad de que los pobladores allí asentados permanecieran en las tierras en las que residían. Se superpuso y subvirtieron otros tipos de territorialidades, modificando la vida cotidiana de los pobladores rurales.

Las estancias, enclaves de propiedad privada en un vasto territorio en construcción -en términos de espacio de gobernanza-, se dedicaron a la cría de ganado y demandaron mano de obra. Por tanto, se convirtieron en espacios atractivos para la población en búsqueda de trabajo, en una zona donde este era escaso: “[...] hasta lo que yo recuerdo y más atrás por lo que me contaba mi viejo, eran buenos la gente de 'La Primavera'. Eran buenos en el sentido 
de generarte un trabajo, de ayudarte, de que la gente de la estancia tenía plata, entonces podía pagar un sueldo" (Entrevista a José, poblador de Villa Traful, Villa Traful, año 2008).

En la configuración del pueblo en aquel entonces y ante la necesidad de conseguir dinerario observamos cómo va cobrando fuerza la idea de las estancias como "benefactoras", dado que eran el acceso a una fuente de trabajo remunerado. Para los pobladores rurales de Traful, la obtención de un salario aseguraba poder pagar los impuestos del PNNH y, por ende, la permanencia en el pueblo - evitando las rupturas familiares-y la continuidad en "su tierra" desarrollando las actividades tradicionales, ya que por lo general las estancias los contrataban en forma estacional.

La distinción propietarios/no propietarios generó una diferenciación en términos de ciudadanía y de derechos, puesto que quienes titularizaron no solo tenían influencia en las instituciones, sino que también eran validados como virtuales autoridades locales. A partir de relatos recogidos durante el trabajo de campo, se señaló que para permanecer en el país debían obtener permisos firmados por los estancieros, los cuales autorizaban y certificaban la "buena conducta" de los pobladores. Los propietarios se constituyeron en autoridades locales referenciadas por el Estado nacional.

\section{Reflexiones finales}

A lo largo de este trabajo, se recuperó a partir de las escasas fuentes documentales de la zona y los relatos de los pobladores de Villa Traful la dinámica de la vida social y el proceso de distribución de la tierra pública en la localidad. Para esto, se describió el proceso de poblamiento de la zona, cómo se fue configurando el territorio, en tanto espacio de gobernanza en paralelo a la consolidación de la propiedad.

Para esto se abordó brevemente el proceso histórico de incorporación 
de la Patagonia al Estado recuperando dos procesos centrales: por un lado la vía militar y los mecanismos de reparto de la tierra. Por el otro, la instauración de instituciones estatales que fueron delineando la ocupación efectiva del territorio por el Estado. Con respecto al primero, se abordó escuetamente la "Campaña al Desierto" con el objeto de describir los mecanismos de reparto de la tierra fiscal y su impacto en Traful. Asimismo, se describieron las normativas que regularon y consolidaron tres tipos de categorías respecto a la relación con la tierra: propietarios, ocupantes precarios e intrusos, las cuales definieron y estructuraron el espacio patagónico, dando prioridad a algunos sectores -generalmente ligados a las elites gobernantes- y desconociendo, así como deslegitimando a otros -generalmente indígenas y migrantes sin capital-. Estas categorías fueron administradas por intermedio de Tierras y Colonias - institución dependiente del poder central- y con la creación de la APN fue transferida la administración del territorio a esta institución.

En este contexto se fueron consolidando por un lado los ocupantes sin título y un pequeño grupo de propietarios privados, quienes crearon grandes estancias en las que se practicaba la ganadería extensiva a gran escala, a diferencia de la practicada por los pobladores indígenas y no indígenas. Asimismo, estos grupos propietarios comenzaron a ofrecer trabajo en las estancias surgiendo con mayor fuerza la noción de asalariamiento.

Finalmente, respecto de la distribución de la tierra, se recuperó a Harvey (2006) quien sostiene que el Estado surge como garante de los intereses de la burguesía que del mismo modo mantiene, fomenta y aplica las relaciones sociales capitalistas, garantizando el derecho de propiedad privada de los medios de producción y de la fuerza de trabajo. En este sentido cabe suponer que la creación del territorio como espacio de gobernanza y la propiedad solo pueden comprenderse en su imbricación o su creación conjunta.

Por lo tanto, en la medida que el Estado legitimó y otorgó poder a los propietarios de la zona de Traful, también se consolidaron como promotores 
de relaciones específicas de trabajo, actuando además como nexo con instituciones estatales. Podemos decir entonces que la construcción territorial de la localidad se caracterizó por la consolidación de un reducido grupo de propietarios, mientras que el resto de los ocupantes no logró la titularización, estableciendo relaciones de poder asimétricas entre ambos.

En relatos recuperados a partir del trabajo de campo en Norpatagonia y específicamente en Villa Traful, se identificaron que estos primeros propietarios extranjeros asentados en la zona a fines del siglo XIX fueron denominados pioneros, mientras que los ocupantes sin título que se asientan en la zona en el mismo período histórico son referenciados como pobladores. Esto sienta las bases para la configuración de una dinámica territorial donde la convivencia está marcada por grandes asimetrías en las cuales se evidencia no una distancia física, sino también social (Bersten, 2014a).

\section{Referencias}

Achilli, Elena (2005). Investigar en Antropología Social. Los desafíos de transmitir un oficio. Rosario: Laborde Editor.

Bersten, Lara (2009). "La provincialización de Neuquén y el traspaso de tierras de la Administración de Parques Nacionales a la Provincia". En El territorio en Perspectiva. Política Pública y Memoria Social en Villa Traful (pp.17-33). Buenos Aires: Secretaría de Políticas Universitarias.

(2014a). Construyendo naturalezas: patrimonio natural y administración sustentable en Villa Traful (Neuquén, Argentina). Tesis de Doctorado. Buenos Aires: Facultad de Filosofía y Letras, Universidad de Buenos Aires. -- (2014b). "Áreas protegidas y desarrollo en Villa Traful (Neuquén, Argentina)”. CEIEAS, Papeles de Trabajo No 27, Universidad Nacional de Rosario. 
Blanco, Graciela (2007). "La ocupación de la tierra pública en Neuquén: política distributiva, formas de tenencia y uso del suelo (1880-1920)". Mundo Agrario. Revista de estudios rurales, 7 (14), 7-14.

Bourdieu, Pierre (2002). "O conhecimiento pelo corpo". En: Pierre Bourdieu, Meditações Pascalianas. San Pablo: Bertrand Brasil.

Bustos Ávila, Carlos. “Apuntes para una crítica de la geografîa política: territorio, formación territorial y modo de producción capitalista”. MS, 2001. Disponible en: http://observatoriogeograficoamericalatina.org. $\mathrm{mx} /$ egal12/Teoriaymetodo/Conceptuales/03.pdf.

Fernandes, Bernardo (2010). "Acerca de la tipología de territorios". En Carlos Rodríguez Wallenius (Ed.), Defensa comunitaria del territorio en la zona central de México. Enfoques teóricos y análisis de experiencias (pp. 173-224). Xochimilco:Juan Pablos Editor.

García, Analía y Bersten, Lara (comps.). (2009). El territorio en Perspectiva. Política Pública y Memoria Social en Villa Traful. Buenos Aires: Secretaría de Políticas Universitarias.

Golab, Raine y Lamperti, Sabrina (s/f). "Contexto Histórico General de la familia de Eusebio Elías Arze”. En R. Golab (Ed.), La saga de los Arze y los Arce. Historia y Genealogía. s/f. Disponible en: http://www. arze-arce.com.ar.

Harvey, David (2006). "A teoría marxista do Estado". En David Harvey (Ed.), A Produçao capitalista do espaço (pp. 75-94). San Pablo: Annablume.

Juárez, Francisco (2005). Historias de la Patagonia, Buenos Aires: Ediciones B.

Lefebvre, Henri (1974). La Production de L'Espace. Paris: Anthropos.

Moraes, Alexandre. “Territorio, poder e justiça: comentários a partir da experiencia brasileira". En Raquel Kristch y Bernardo Ricupero (Orgs.), Força e Legitimidade: ¿Novas Perspectivas? (pp. 113-139). San Pablo: Humanitas. 
Moyano, Marisa (2003). "Escritura, frontera y territorialización en la cons trucción de la Nación. Ciberletras". Revista de Crítica literaria y de cultura, 9, 75-94.

Silveira, Mario y Guindon, Jacqueline (2008). Esculpidos en el tiempo. Arqueología e historia de Traful y Cuyín Manzano. Buenos Aires: Educo.

Valverde, Sebastían, García, Analía y Bersten, Lara (eds.). (2008). Relatos patagónicos. Historias familiares en la construcción del espacio Social en Villa Traful. Córdoba: Ferreyra Editor.

Fuentes documentales consultadas/Archivos

Archivo General de la Nación (AGN). Censos Nacionales.

\section{Administración Parques Nacionales}

Censo de Pobladores del Parque Nahuel Huapi del año 1934.

Censo de Pobladores del Parque Nahuel Huapi del año 1965.

Propiedades Privadas dentro del PNNH, S/F. 